\title{
IMPROVEMENT OF PERFORMANCE CHARACTERISTICS OF ETHANOL MOTOR FUELS THROUGH USE OF ADDITIVES BASED ON NANOSCALE CARBON CLUSTERS
}

\author{
Olga Haidai \\ Institute of Bioorganic Chemistry and Petrochemistry National Academy of Sciences of Ukraine \\ 50 Kharkiv highway, Kyiv, Ukraine, 02660 \\ Gaidaj@ukr.net \\ Vladimir Pilyavskiy \\ Institute of Bioorganic Chemistry and Petrochemistry National Academy of Sciences of Ukraine \\ 50 Kharkiv highway, Kyiv, Ukraine, 02660 \\ pilvs@yandex.ua \\ Yevgenij Shelud'ko \\ Institute of Bioorganic Chemistry and Petrochemistry National Academy of Sciences of Ukraine \\ 50 Kharkiv highway, Kyiv, Ukraine, 02660 \\ fluortribo@rambler.ru \\ Yevgenij Polunkin \\ Institute of Bioorganic Chemistry and Petrochemistry National Academy of Sciences of Ukraine \\ 50 Kharkiv highway, Kyiv, Ukraine, 02660 \\ polunkin@i.ua
}

\begin{abstract}
A new way to overcome the disadvantages of ethanol motor fuels by introducing of multifunctional additives based on carbon nanoscale clusters in their composition is given. It is shown that the modified nanoclusters contribute to the formation of supramolecular structure of ethanol fuels in the form of solvent domains around the nanoparticles. Orientation local ordering of these supramolecular structures changes such physicochemical properties of oxygenate fuels as dielectric constant and the load-bearing capacity of the liquid phase in the dynamic mechanical load.

The influence of synthetic carbon spheroidal clusters on the corrosive properties of ethanol fuels is studied. It is shown that by using small amounts $(0.01 \% \mathrm{wt}$.) of nanocluster-based additives in the composition of mixed fuel E- 85 it is unnecessary to introduce the anticorrosion additives.

The effect of nanocarbon clusters on the tribological properties of ethanol motor fuels is studied. A decrease in damage of the metal surface for friction pairs of the fuel pumps is observed with the introduction of carboxylic nanoclusters into the ethanol fuel. This indicates the occurrence of friction processes in the hydrodynamic regime due to the increased bearing capacity of the fuel.

It is shown that the introduction of additives based on carbon nanoscale clusters into the ethanol fuel allows to create a high-performance motor fuel with improved performance.

Keywords: ethanol fuel, nanoscale carbon clusters, structure formation, corrosion properties, tribological characteristics of motor fuels.

\section{Introduction}

To adjust the performance characteristics (anti-wear, anti-corrosion, detergent and energy) of automobile and aircraft motor fuels it should be added a package of additives in their structure - a set of chemical compounds with different mechanisms of action. Thus, inhibitors should be added in the composition of fuel for oxidation inhibition of molecules of the liquid fuels during the storage; antiknock components and combustion promoters are used to regulate the speed and completeness of fuel combustion in engines; corrosion and anti-wear additives are necessary to reduce the negative impact of fuel on the wear of engines [1].

In recent years environmental requirements for the motor fuel composition are continually stricter, in particular sulfur content. In the European standard EN590:2009 (E) a sulfur content in 
gasoline is regulated by the value of $50 \mathrm{ppm}(0.005 \% \mathrm{wt}$.), and for gasoline with ultra-low sulfur content $-10 \mathrm{ppm}(0.001 \% \mathrm{wt}$.) [2]. Anti-wear properties of fuels are reduced due to desulfurization, which leads to faster wear of engines, primarily fuel equipment.

Particularly acute problem of accelerated wear of fuel equipment and accidents of automobile engines is appeared for using alternative ethanol-based motor fuels.

Ethanol as an alternative fuel has many advantages compared to the traditional fuel [3, 4]. In particular, the use of ethanol in the mixed gasoline eliminates the need to use highly toxic metal antiknock additives and methyl tert-butyl ether (MTBE). But corrosiveness and anti-wear properties of the ethanol are worse than gasoline, so the use of ethanol in the motor fuel composition at a concentration more than $12 \%$ can have a negative impact on engine life $[5,6]$.

To improve the anti-wear properties of fuels is possible by the use of additives, which have proven themselves in the composition of motor oils. Additives modify metal friction surfaces by creating friction adsorption films (surfactants) or by chemical interaction with the metal (reactive substances). Metal complex compound (for example, zinc bis-dialkyldithiophosphate) are widely used In the world in order to improve the tribological performance of lubricants [7, 8].

However, this type of additives contains sulfur, phosphorous and heavy metal atoms. Their use in the composition of motor fuels leads to an increase in sediments (lacquer, sludge and varnish) on the surfaces of engine parts and premature out of service. Furthermore, such substances when burned with fuel increases the toxicity of emissions from motor vehicles. So now, the use of traditional additives in motor fuels is limited by legal and has no future [1].

A fundamental solution of the problem of improving the performance characteristics of modern motor fuels requires a new unconventional approach. Motor fuels are not molecular solutions. They are the polydisperse system, consideration of which should be carried out from the standpoint of colloid chemistry and nanochemistry. This approach will create clean and efficient additives for new motor fuels.

The purpose of this study was to determine the effect of microconcentrations of carbon nanoclusters in the composition of ethanol fuel on its corrosion and anti-wear properties.

Synthesis of various forms of carbonic nanomaterials (fullerenes, nanotubes, nanofibers, etc.) and research of the possibilities of using them in various fields of science and technology is one of the current trends in the world for the work of research teams [9-13]. Technologies to obtain any ultrafine materials are laborious $[14,15]$. This is true for nanomaterials of carboxylic fulleroid type (singlespheroidal fullerenes and multi-spheroidal clusters-onions), and, therefore, a great interest have the areas of use in which to achieve substantial results (macro effects) quite minimal amounts of these nanomaterials. These areas include the use of them in the energy sector, including as components of automobile and aircraft motor fuels.

In this article nanoscale carbon structures are investigated as the microadditive to the ethanol fuel for the improvement of operational properties. They are consisting of multilayer carbon spheres - Onions (CNOs - carbon nanoonions) [16-19].

Owing to their poor solubility (less than $0.001 \% \mathrm{wt}$.) in the alcohol and hydrocarbon liquids of low viscosity, the influence of these substances on the characteristics of motor fuels has not been studied in the world.

\section{Materials and Methods}

Nanomaterial as carbon multilayer spherical clusters-onions was received by high-frequency discharge-pulsed synthesis on the iron electrodes using mixture of light hydrocarbons as the basic material (acetylene and propane-butane mixture) [20].

Based on the analysis of the scientific literature [21], the optimal method of purification and recovery of carbon nanoclusters was chosen. It was tested previously and gave the best results.

Purification and release of the onions included the following steps:

1. In order to remove amorphous carbon sample was oxidized in high temperature air flow $\left(70 \mathrm{~cm}^{3} / \mathrm{min}\right)$ for 2 hours at $350{ }^{\circ} \mathrm{C}$.

2. The sample was treated with $36 \% \mathrm{HCl}$ solution for 24 hours and centrifuged for washing the catalyst residues. 
3. Sample processing by $0.2 \%$ solution of benzalkonium chloride (cationic active surfactants) for 4 hours with dispersing using an ultrasonic disperser (10 min.) and centrifugation $(5 \times 30 \mathrm{~min}$.) at $3500 \mathrm{rev} / \mathrm{min}$.

4. Two-time filtration of the solution through a filter ( $\varnothing 400 \mathrm{~nm}$ long).

5. Evaporation of water in the water bath.

Chemical modification of the surface of the carbon clusters by bromination was carried out to improve the stability of the nanoclusters in the ethanol fuel.

Bromination of the resulting product was carried out at a temperature of $20-22{ }^{\circ} \mathrm{C}$ for 60 days in an excess of liquid bromine. Thereafter, the residual bromine was removed by evacuation at a temperature of $20-22{ }^{\circ} \mathrm{C}$, sediments were dissolved in acetone and filtered. According to the results of chemical analysis, bromine content in the synthesized product was $24.5 \%$ wt.

The obtained brominated nanocarbon material formed stable dispersions in alcohol and organic solvents.

Surface topography and the features of the association of individual nanoparticles into aggregates of various sizes were examined by scanning electron (SEM), transmission electron (TEM) and atomic force microscopy (AFM) [22].

Used analysis methods have allowed to obtain images of the sample surface with high resolution, followed by computer processing of acquired images, which revealed quantitative information about the structure of the object.

Capacitance measurement was performed using an AC bridge circuit.

The method of dynamic coherent light scattering was used for experimental evaluation of the size of the solvated structures (domains) of the molecules of the dispersion medium around carbonic nanoparticles $[23,24]$. This method allowed to investigate particles in liquids in a wide range of sizes, research aggregation and dissociation of macromolecules, which allowed to determine the dependence of the diameter of the solvation shell around the nanoparticles of carbonic clusters from chemical nature of the solvent.

\section{Research of ethanol fuel containing nanocluster-based additive}

To investigate brominated onions as a multifunctional additive to ethanol fuel ponsored the authors prepared the basic formulation of fuel ethanol E-85 containing $85 \%$ vol. ethanol and $15 \%$ vol. oil gasoline with 95 octane number.

For obtaining of the additive to ethanol fuels modified nanoclusters CNOs-Br was dissolved in absolute ethanol and introduced into the basic fuel formulation E-85 at a concentration of $0.01 \% \mathrm{wt}$.

Investigation of the effect of nanoscale cluster compounds on the bearing capacity of the liquids were conducted by the method ASTM D2783-03 (2014) [25] using four-ball wear test system (ЧШМ-К1 (М) “Technopromkomplekt”, Ukraine) in terms of the critical load. Test conditions: rate speed of the loaded upper ball in reference to the three stationary balls is $1500 \mathrm{~min}^{-1}$, the test time at each load is 10 seconds.

To assess the corrosive effect of biofuel E-85 test method was used on a copper plate in accordance with GOST 6321-92 (ISO 2160-85) [26].

3 types of fuel were used to test for corrosiveness of mixed fuel:

1 - mixed fuel E-85 - basic formulation;

2 - mixed fuel E-85 with the addition of additives of modified nanoscale carbon clusters CNOs-Br;

3 - standard isooctane - the comparison sample (Haltermann GmbH, Germany).

According to the test method [26], prepared copper plates are dipped in the three fuel samples and aged for 3 hours at $50{ }^{\circ} \mathrm{C}$. Then the plate is removed, washed and compared with a standard. After the initial evaluation of corrosion of E-85 biofuel sample on copper plate, plates again places in a test tube with biofuel and standard fuel for assessing future trends of damaged copper plates. 


\section{Research results of performance characteristics of ethanol motor fuels}

In assessing brominated onions by SEM and TEM methods it was revealed that synthesized carbon nanoparticles had the shape of a sphere with a diameter of 5-40 $\mathrm{nm}$.

A detailed study of the obtained samples of carbon nanomaterials using AFM showed that the average size of the nanoparticles is in the range 5-9 $\mathrm{nm}$.

When studying solutions of synthesized nanoparticles by the method of dynamic scattering of the laser light, it was found that the hydrodynamic diameter of carbon nanoclusters solvated in alcoholic solvents is significantly exceed the size of individual particles and additives and it was 20-1000 nm depending on the nature of the solvent (Table 1).

\section{Table 1}

The average size of solvated nanoclusters - onions in different solvents

\begin{tabular}{cc}
\hline Solvent & Particle size with solvate coat, $\mathbf{n m}$ \\
\hline ethanol & 1000 \\
N-methyl-2-pyrrolidone & 950 \\
dimethylformamide & 220 \\
dioxane & 28 \\
benzyl alcohol & 21
\end{tabular}

In the media, which molecular structure contains a six-membered ring (benzyl alcohol, dioxane), solvent molecules form only monolayer around a fulleroid nanoparticles. These rings due similarity to the flat 6-membered structural fragments of carbon clusters are planar to such fragments of the nanoparticles and inhibit their unsaturated double bonds $\mathrm{C}=\mathrm{C}$ with increased electron density.

In the solvents, which molecules have a linear structure, in particular in ethanol, multilayer solvate shells are formed around carbon nanoclusters due to induced polarization of the solvent molecules.

Formation of ordered supramolecular structures - domains - is accompanied by a more induced polarization of the molecules due to their orientation and displacement of electron density under the influence of the polar (or polarized with solvation) brominated carbon nanoparticles (Fig. 1).

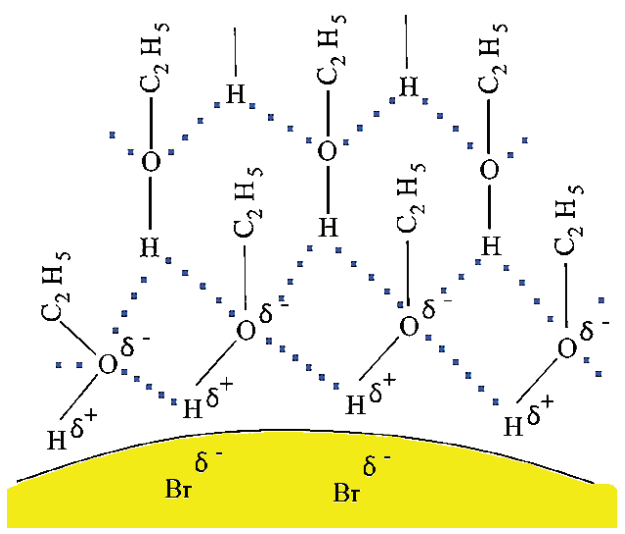

Fig. 1. Orientation ordering of ethanol molecules under the influence of polar nanoparticles - brominated spheroidal carbon clusters

The ordered domain structure with the orientation of hydrocarbon fragments of solvent molecules to the outer surface of such supramolecular objects, and the hydroxyl groups - to centerformed nanocarbon particles significantly alters the physical and chemical properties and tribochemical characteristics. 
The proposed model of local orientational ordering of ethanol molecules around carbon nanoparticles confirmed experimentally by nonmonotonic dependence of increase of the bearing capacity (Fig. 2, curve 1) and the simultaneous reduction of electrical capacitance (Fig. 2, curve 2) of alcohol solutions under the influence of low concentrations of carbon nanoclusters.

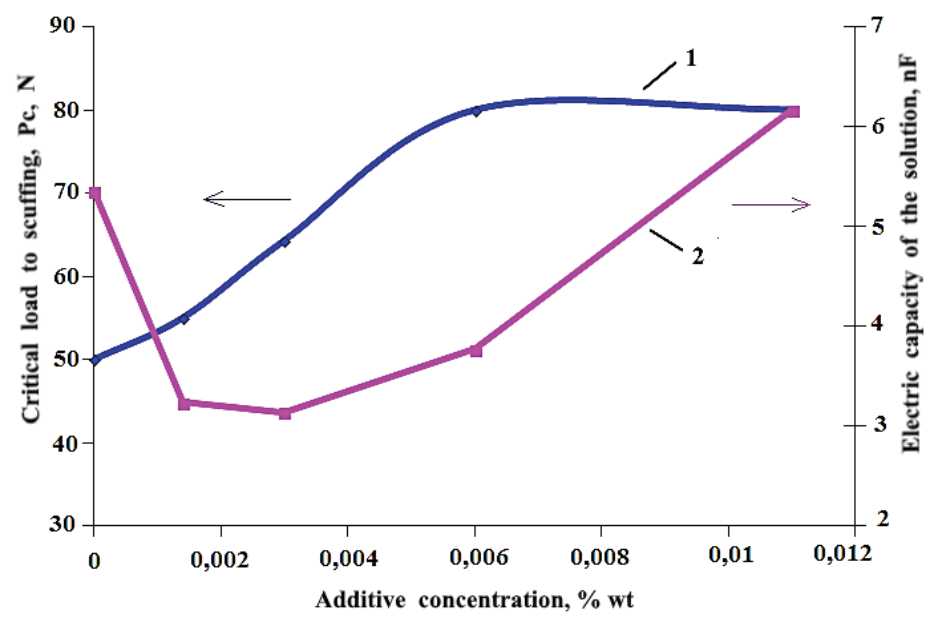

Fig. 2. Synchronous change of bearing capacity (curve 1) and electrical capacitance (curve 2) of ethanol depending on concentration of carbon nanoclusters.

\section{Discussion of research results}

Let's consider how changes in these characteristics of alcoholic solutions affect the processes of corrosion and wear.

\section{1. Corrosiveness of ethanol fuels}

Electric capacitance of the flat capacitor in the SI system is directly proportional to the permittivity of the medium:

$$
\mathrm{C}=\varepsilon \varepsilon_{0} \mathrm{~S} / \mathrm{d}
$$

where $\varepsilon$ - permittivity between the capacitor plates; $\varepsilon_{0}$ - vacuum permittivity; $\mathrm{S}$ - the value of the surface area of the plate (less, if they are not equal); $d$ - distance between the plates [27].

Because electric capacitance of ethanol fuel is reduced at the adding of additive of nanoscale carbon clusters (Fig. 2), then solution permittivity is decreases too. Permittivity reducing for the ethanol fuel when adding modified carboxylic nanoclasters indicates a decrease in the electrical conductivity of the medium, and accordingly, the diffusion rate of ions in that medium. Thus, domain formation in the dispersion medium on the basis of nanocarbon particles should inhibit corrosion processes

Experimental results obtained in the study of the corrosiveness of the ethanol fuel E- 85 with the addition of additives of the nanoclusters and without their adding confirm this hypothesis (Fig. 3) [28].

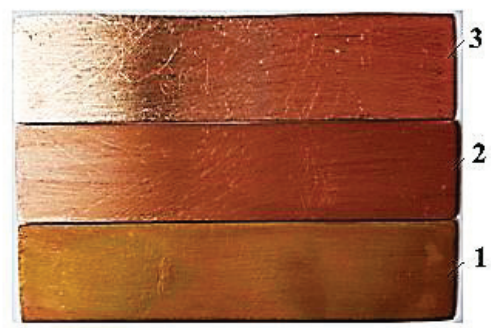

Fig. 3. Research results of corrosiveness fuel tests: $1-$ E-85 (basic formulation), $2-\mathrm{E}-85+\mathrm{CNOs}, 3$ - isooctane (standard) 
As shown in Fig. 3, in E-85 fuel without additives (1) there is an intensive corrosion of the sample - a copper plate coated with gold spots with a green tint; the corrosion degree -2 . Color of the copper plate in the ethanol fuel E-85 with the additive (2) is unchanged - a light orange with a slight tarnish; the corrosion degree - 1 that is allowed by normative documentation [29]

\section{2. The tribological characteristics of ethanol fuels}

Typically, additive effect on the wear properties of liquid lubricants explain the change of mechanical properties of the contacting surfaces as a result of chemical interaction of additive molecules with metal surfaces with the creation of so-called intermediate (third) phase [30].

Developed concept [31] suggests a mechanism for changing the anti-wear properties of liquid media due to orientational ordering of solvent molecules around the nanoclusters.

The value of the critical load to scuffing of friction surfaces, measured at tribological tests, in reality always is an integral characteristic, which reflects the total contribution to the frictional resistance to damage of the metal surfaces of two components - the bearing capacity of the liquid layer and the bearing capacity of the protrusions of metal surfaces. Adding to the liquid phase of small amounts (about $0.001-0.01 \% \mathrm{wt}$.) of the additive does not alter the roughness and mechanical properties of the surfaces, but effect on the bearing capacity of the liquid layer.

The bearing capacity of the liquid layer (liquid dynamic strength) is due to the occurrence of "oil wedge" between the metal surfaces - excess pressure in the contact area. As shown in [32], a pressure surge generated by retarding liquid flow near a solid friction surface can be calculated according to the Zhukovsky formula for pressure changes in the case of water hammer:

$$
\Delta \mathrm{P}=\rho \cdot \mathrm{V}_{0} \cdot \mathrm{C}
$$

where $\Delta \mathrm{P}$ - pressure increase in $\mathrm{N} / \mathrm{m}^{2} ; \rho$ - density of the medium $\mathrm{kg} / \mathrm{m}^{3} ; \mathrm{V}_{0}$ - oncoming liquid flow rate, $\mathrm{m} / \mathrm{s} ; \mathrm{C}$ - elastic deformation rate (sound propagation) in the liquid.

Adding of microquantities of the nanoparticles into ethanol did not result in significant changes in density or the sliding speed, but can influence the sound speed in the medium.

For example, in $[33,34]$, it was shown that in the oriented polymers when molecular chains are aligned parallel to the direction of sound propagation, sound speed increases sharply in comparison with randomly placed molecules.

A similar mechanism is realized in our case: the orientational ordering of molecules around the nanoparticles in the form of chains with hydrogen bonds leads to an increase of the elastic perturbation rate in the environment compared to the situation for non-oriented molecules.

Tests of car fuel pump resource were carried out at their work with a variety of fuels to compare the effect of additives of carboxylic nanoclusters on anti-wear properties of ethanol motor fuels [35].

The friction surfaces of the fuel pumps after working on three types of fuel (Fig. 4) were examined for test and measuring complex developed in the research laboratories of nanotribotehnology in National Aviation University (Kyiv, Ukraine), consisting of the tribological test system ACK-01, a laser differential phase scanning microscope-profilometer LDPSMP, multistage testing methods and scanning electron microscope SEM-106I.

The maximal wear was observed on the fuel pump bushings in the case of E-85 ethanol fuel without addition of additives of nanoclusters (Fig. 4, (I)).

On the pump bushings after working on hydrocarbon motor gasoline A-95 and ethanol fuel E-85 with the addition of additives of synthesized carbon nanoclusters (Fig. 4, III) there is less tear-outs and no damage in the form of scratches. This indicates the occurrence of friction in the hydrodynamic regime due to the increased bearing capacity of the fuel. 


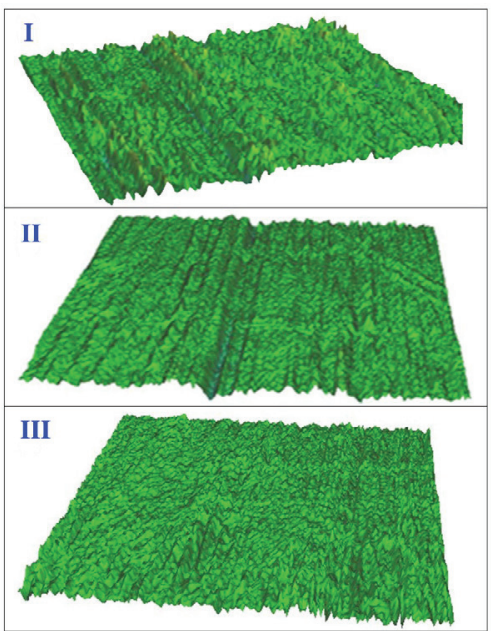

Fig. 4. Comparative characteristics of friction surfaces for fuels:

I - ethanol fuel E-85 (basic formulation); II - gasoline A-95 (Ukraine);

III - ethanol fuel E-85+CNOs

\section{Conclusions}

A new concept of the influence of small amounts of additives based on brominated carbon nanosized clusters on the change of tribological and corrosive properties of ethanol motor fuels is presented and proved in the article. Improvement of the performance characteristics of ethanol motor fuels in the presence of nanosized additives is explained by a change in the supramolecular structure of fuels by formation of domains in the dispersion solvent medium around the nanoparticle of the additive. Thus, changing the fuel structure, an additive in microquantities on the basis of nanocarbon clusters shows multifunctional effect.

It is shown that slowing of corrosion processes caused by the decrease of the medium permittivity by the addition of nanoscale carbon clusters in ethanol fuel. It is determined that the use of nanocluster-based additives in ethanol fuel composition does not require additional corrosion inhibitors.

Tribological tests show that adding of synthesized modified carbon multilayer spheroidal clusters in ethanol motor fuel with reduces the wear of metal friction pairs. Thus, for improving the tribological characteristics of ethanol motor fuels can be used not toxic metal-containing additives, but effective and environmentally friendly additives for new motor fuels.

\section{References}

[1] Danilov, A. M. (2010). Primenenie prisadok v toplivah. Sankt-Peterburg: KHIMIZDAT, 365.

[2] EN590:2004 (2009). Automotive fuels. Diesel. Requirements and test methods. European committee for standartization, 12 .

[3] Vnukova, N. V., Barun, M. V. (2011). Al'ternatyvne palyvo yak osnova resursozberezhennya i ekobezpeky avtotransportu. Al'ternativnie istochniki energii, 9 (91), 45-55.

[4] Saydahmetov, S. I., Karpov, S. A. (2007). Issledovanie smesevyh kompoziciy oksigenatov s etilovim spirtom v kachestve komponenta avtomobilnih topliv. Neftepererabotka i neftehimiya, 10, 29-32.

[5] Boichenko, S. V., Boichenko, M. S., Lichmanenko, O. G., Kaban S. M. (2015). Vplyv dobavok alifatychnyh spyrtiv na vlastyvosti benzyniv: analitychnyy oglyad. Naukoyemni tehnologii, 1 (25), 86-92.

[6] Kovtun, G. A. (2005). Al'ternatyvni motorni palyva. Visnik Nacional'noy akademii nauk Ukraini, 2, 19-27.

[7] Kuz'mina, G. N., Naumov, A. G., Parenago, O. P. (2015). Smazochnie svoystva maslyanih SOTS, soderzhashchih v svoem sostave tribologicheski aktivnie prisadki. Trenie i iznos, 36 (4), 409-414.

[8] Mang, T., Bobzin, K., Bartels, T. (2010). Industrial Tribology. Wiley, 644. doi: 10.1002/9783527632572

[9] Notarianni, M., Liu, J., Vernon, K., Motta, N. (2016). Synthesis and applications of carbon nanomaterials for energy generation and storage. Beilstein Journal of Nanotechnology, 7, 149-196. doi: 10.3762/bjnano.7.17

[10] Liu, W.-W., Chai, S.-P., Mohamed, A. R., Hashim, U. (2014). Synthesis and characterization of graphene and carbon nanotubes: A review on the past and recent developments. Journal of Industrial and Engineering Chemistry, 20 (4), 1171-1185. doi: 10.1016/j.jiec.2013.08.028 
[11] Deshmukh, A. A., Mhlanga, S. D., Coville, N. J. (2010). Carbon spheres. Materials Science and Engineering: R: Reports, 70 (1-2), 1-28. doi: 10.1016/j.mser.2010.06.017

[12] Mishchenko, S. V., Tkachev, A. G. (2008). Uglerodnye nanomaterialy. Proizvodsdtvo, svoystva, primenenie. Moscow: Mashinostroyenie, 320.

[13] Otsubo, Y., Fujiwara, M., Kouno, M., Edamura, K. (2007). Shear-thickening flow of suspensions of carbon nanofibers in aqueous PVA solutions. Rheologica Acta, 46 (7), 905-912. doi: 10.1007/s00397-007-0173-Z

[14] Bartelmess, J., Giordani, S. (2014). Carbon nano-onions (multi-layer fullerenes): chemistry and applications. Beilstein Journal of Nanotechnology, 5, 1980-1998. doi:10.3762/bjnano.5.207

[15] Echegoyen, L., Ortiz, A., Chaur, M. N., Palkar, A. J. (2010). Carbon Nano Onions. Akasaka/Chemistry of Nanocarbons, 463-483. doi: 10.1002/9780470660188.ch19

[16] Zhang, C., Li, J., Liu, E., He, C., Shi, C., Du, X., Zhao, N. (2012). Synthesis of hollow carbon nanoonions and their use for electrochemical hydrogen storage. Carbon, 50 (10), 3513-3521. doi:10.1016/j.carbon.2012.03.019

[17] Kuznetsov, V., Moseenkov, S., Ischenko, A., Romanenko, A., Buryakov, T., Anikeeva, O., Lambin, P. (2008). Controllable electromagnetic response of onion-like carbon based materials. Physica Status Solidi (b), 245 (10), 2051-2054. doi: 10.1002/pssb.200879603

[18] McDonough, J. K., Gogotsi, Y. (2013). Carbon Onions: Synthesis and Electrochemical Applications. Interface Magazine, 22 (3), 61-66. doi: 10.1149/2.f05133if

[19] Wepasnick, K. A., Smith, B. A., Bitter, J. L., Howard Fairbrother, D. (2010). Chemical and structural characterization of carbon nanotube surfaces. Analytical and Bioanalytical Chemistry, 396 (3), 1003-1014. doi: 10.1007/s00216-009-3332-5

[20] Beliy, N. M., Boguslavsky, L. Z., Zelinskaya, G. M. (2013). Strukturno-energeticheskie aspekti sinteza yglerodnih nanomaterialov visokovoltnimi elektrorazryadnimi metodami. Khimicheskaya tehnologiya neorganicheskih i organicheskih veshchestv, teoreticheskie osnovi, 56 (7), 98-104.

[21] Zhou, J., Shen, Z., Hou, S., Zhao, X., Xue, Z., Shi, Z., Gu, Z. (2007). Adsorption and manipulation of carbon onions on highly oriented pyrolytic graphite studied with atomic force microscopy. Applied Surface Science, 253 (6), 3237-3241. doi: 10.1016/j.apsusc.2006.07.012

[22] Vlasov, A. I. (2011) Elektronnaya mikroskopiya. Moscow: MGTU im. N. E. Baumana, 168

[23] Kulikov, K. G., Koshlan, T. V. (2015). Opredelenie razmerov kolloidnyh chastic pri pomoshchi metoda dinamicheskogo rasseyaniya sveta. Zhurnal tehnicheskoy fiziki, 85 (12), 26-32.

[24] Vogel, R., Willmott, G., Kozak, D., Roberts, G. S., Anderson, W., Groenewegen, L., Trau, M. (2011). Quantitative Sizing of Nano/Microparticles with a Tunable Elastomeric Pore Sensor. Anal. Chem., 83 (9), 3499-3506. doi: 10.1021/ac200195n

[25] ASTM D2783-03 (2014). Standard Test Method for Measurement of Extreme-Pressure Properties of Lubricating Fluids (Four-Ball Method).

[26] GOST 6321-92. Engine fuels. Method for copper strip test.

[27] Bazeev, E. T., Varlamov, G. B., Vol'chin, I. A. (2006). Energetika: istoriya, nastoyashchee i budushchee, Poznanie i opyt - put' k sovremennoy energetike. Kyiv: ADEF-Ukraina, 350.

[28] Haidai, O. O., Pilyavskiy, V. S., Polunkin, E. V. (2016). Polipshennya ekspluataciynih vlastyvostey etanol'nih motornih palyv mikrodozami karbonovyh sferoidal'nih klasterov. Naukoyemni tehnologii (Science-based technologies), 1, 3-8.

[29] CWA 15293 (2005). Automotive fuels. Ethanol E85. Requirements and test methods.

[30] Frolov, K. V. (2008). Sovremennaya tribologiya: itogi i perspektivi. Moscow: Izdatel'stvo LKI, 480.

[31] Piljavsky, V. S., Kovtun, G. A., Polunkin, E. V. (2009). The tribological properties of modified fullerenes in different disperses mediums. XI International Conference "Hydrogen Materials Science and Chemistry of Carbon Nanomaterials" (ICHMS'2009), 478.

[32] Pilyavskiy, V. S., Polunkin, E. V., Kameneva, T. M. (2010). Dinamicheskaya nesushchaya sposobnost' zhidkih spirtov, Kataliz i neftehimiya, 18, 45-49.

[33] Pavlinov, L. I., Rabinovich, I. B., Pogorelko, V. Z. (1968). Skorost' zvuka I szhimaemost' sopolimerov metilmetakrilata s metakrilovoy kislotoy. Visokomolekulyarnie soedineniya, 6, 1270-1276.

[34] Ryabov, A. V., Emel'yanov, D. N., Semchikov, Yu. D. (1967). Trudi po khimii i khim. tehnologii, 1 (17), 139-143.

[35] Haidai, O. O., Khimach, N. Yu., Pylyavskyy, V. S. (2016). Novi pidhodi do stvorennya alternatyvnih motornih palyv z ponovlyuvanoi syrovyny. ScienceRise, 6 (2 (23)), 13-21. doi: 10.15587/2313-8416.2016.71955 